\title{
SCARABIASIS IN CHILDREN: A PROSPECTIVE STUDY OF 6 CASES
}

\author{
Mohammed M. T. P1, Sudhakaran K2, Venugopalan A. $K^{3}$
}

1 Professor \& HOD, Department of Paediatrics, Academy of Medical Sciences \& Medical College, Pariyaram, Kannur, Kerala. 2 Professor, Department of Paediatrics, Academy of Medical Sciences \& Medical College, Pariyaram, Kannur, Kerala. ${ }^{3}$ Assistant Professor, Department of Entomology, Academy of Medical Sciences \& Medical College, Pariyaram, Kannur, Kerala.

\begin{tabular}{l}
\hline ABSTRACT \\
BACKGROUND \\
Scarabiasis is a rare condition where beetles fly away from the anus during defecation or wriggle out from freshly passed \\
stools.
\end{tabular}

\section{OBJECTIVES}

1. To determine the clinico-epidemiological characteristics of scarabiasis in children.

2. To observe the usefulness of neem oil application over the perineum, as a treatment.

\section{METHOD}

Prospective observational hospital based study conducted in a tertiary referral hospital in North Kerala. 6 children presented over a period of 15 years with complaints of passing live flies per anus were included in the study.

\section{RESULTS}

The flies were identified as dung beetle. The children belonged to low middle income class who play outdoors without wearing under garments. Physical examination and investigations were unremarkable. Simple measures like improving personal hygiene, applying Neem oil over perineum and wearing tight undergarments were only needed as treatment. None of them had received saline purgatives or oral metronidazole, as was the usual treatment.

\section{CONCLUSION}

Scarabiasis is a rare condition in which live flies pass out of anus. Cases were usually managed with saline purgatives and oral metronidazole. In our study, we had not given any medicines, other than application of Neem oil over the perineum and instruct the children to wear tight undergarments, which was found to be quite useful.

\section{KEYWORDS}

Dung Beetle, Scarabiasis, Scarabidae.

HOW TO CITE THIS ARTICLE: Mohammed MTP, Sudhakaran K, Venugopalan AK. Scarabiasis in children: A prospective study of 6 cases. J. Evolution Med. Dent. Sci. 2016;5(37):2260-2261, DOI: 10.14260/jemds/2016/525

\section{INTRODUCTION}

Scarabiasis is a condition where beetles temporarily infest the digestive tract of humans. Scarabs usually fly away from the anus after defecation.(1) Majority of the doctors are not aware of this repulsive complaint and usually ignore and argue with the parents that such a condition is impossible. Scarabiasis mostly seen in children of tropical countries, between the age group of 2 to 5 years. This beetle is closely related to the Dung beetle which infest the cow dung and rolls the dung to a small round ball like structure which is commonly seen close to cattle sheds. Cases of Scarabiasis have been reported from Asian countries like India and Sri Lanka. In India maximum number of cases have been reported from North-Eastern states like West Bengal and Tripura. $^{2}$

Financial or Other, Competing Interest: None.

Submission 27-03-2016, Peer Review 20-04-2016,

Acceptance 26-04-2016, Published 09-05-2016.

Corresponding Author:

Mohammed M. T. P,

Professor \& HOD,

Department of Paediatrics,

Academy of Medical Sciences \& Medical College,

Pariyaram, Kannur,

Kerala.

E-mail:drmtpmohd@yahoo.com

DOI: $10.14260 /$ jemds/2016/525

\section{AIMS AND OBJECTIVES}

- To determine the clinical and epidemiological characteristics of scarabiasis in children.

- To observe the usefulness of neem oil application over the perineum, as a treatment.

\section{MATERIALS AND METHODS}

The study was a prospective observational study conducted at a tertiary referral hospital of North Kerala, Pariyaram Medical College Hospital, between the period of January $1^{\text {st }}$, 2001 to December 31st 2015 . 6 children with complaints of passing live flies in stools were analysed. A detailed history and physical examination including anthropometry was carried out in all patients. Base line investigations including $\mathrm{CBC}$, stool routine examination for RBCs, WBCS, ova, cyst etc. were done in all the 6 children.

The insects were sent to the Entomology Department for identification. Sigmoidoscopy or colonoscopy were not done in any of the patients due to non-availability of the facility. All the children were treated with simple measures like, improving personal hygiene and application of 'Neem Oil' over the perineum and wearing tight undergarments while playing out doors and during sleep, for the following 6 weeks. The children were followed up weekly for 6 weeks for any persistence or recurrence of the problem. In all the 6 patients, stools were free of flies with in the first 2 weeks. 


\section{RESULTS}

6 children were analysed during a period of 15 years. Out of these 4 were males (66.6\%) and 2 females (33.3\%). The presenting complaints for all the 6 children were passing live flies in stool, during the previous 1-2 weeks. The parents of the children didn't believe the symptoms initially as they thought it was impossible. Mild periumbilical pain was the only associated symptom. There was no history of loose stools, vomiting or indigestion. 2 out of the 6 children (33.3\%) had history of pica. 5 children belonged to lower middle income group and only one from upper middle class.

There was history of playing outdoor for prolonged time without wearing trousers or under garments for all the children. Complete blood count and stool routine were normal in all the children. The insects were identified from the Entomology Department as dung beetles, belonged to the family, Scarabidae and species Onthophagus.

None of these patients were treated with saline purgatives or oral metronidazole as was practiced earlier. ${ }^{3}$ Simple measures like improving personal hygiene, applying Neem oil over perineum to repel the flies away, and wearing tight under garments, for the following 6 weeks, were only needed to treat the condition. On weekly follow up for 6 weeks none of the children had persistence or any recurrence of the complaint.

\section{DISCUSSION}

Scarabiasis is a rare condition, even though case series were reported previously.2,3 This problem is mostly seen in children between the age group of 2 to 5 years. The beetle belongs to the family-Scarabidae. Two species are identified in India, Onthophagus bifascicatus and Coccobius mutans. The proposed possibility of human infestation was the entry of the larvae through the rectum and its development in the colon into adult beetles which then escape and fly out of the rectum. It is also hypothesized that, the adult beetles are attracted to the peculiar odour of faeces of some children and enter the rectum through the anus of children sleeping on the floor close to cattle shed, without underclothes and sometimes partially open anus. They do not actually colonize the gut, as no larvae or eggs have been detected in the stools. The beetle simply stays inside the lower G.I, tract and exits. The beetles are ectoparasites and hence they do not invade the mucosa. ${ }^{3}$

The suggested treatment was metronidazole and saline purgatives for killing the larvae. ${ }^{3}$ but in our study we have not given any oral medicines or saline purgatives, instead the mothers were instructed to apply Neem oil over the perineum of the child and to use tight undergarment.
Neem oil is extracted from the neem plant (Azadirachta indica A. Jussieue). Azadirachtin is the important ingredient in neem oil and it is used to prepare a non-toxic, organic and environment friendly pesticide.4,5 Neem is considered harmless to humans, and has been approved by the U.S. Environmental Protection Agency for use on food crops. ${ }^{6}$ The unpleasant garlic/sulphur odour of the neem oil repulses the beetle away. So it can be used as a secondary prevention in scarabiasis, so that the beetle will not get further access in to the lower GI tract. Disappearance of the beetle from the stool within 2 weeks of application of neem oil, without any enteral or parenteral medicines, corroborates the view that it is the adult beetle and not the larva that infests gut.

\section{CONCLUSIONS}

Scarabiasis is a rare condition in which live flies pass out of anus, and is mostly seen in children who play outdoor for prolong hours without wearing undergarments. The condition can be managed without saline purgatives or oral metronidazole, as practised earlier. Application of neem oil, a nontoxic and harmless preparation, over the perineum was observed to be useful in repelling the fly away and thereby can be used as a secondary prevention. The possibility of the adult beetle entering the gut is more likely than the larva as the pathogenic mechanism. However well conducted studies with more number of patients are needed before recommending neem oil as a replacement to previous treatment options.

\section{REFERENCES}

1. Scarabiasis Wikipedia. https://en.wikipedia.org/wiki/Scarabiasis.

2. Majumder N, Datta SS. Scarabiasis in children: study from rural north-east India. Indian Journal of Medical Specialities 2012;3(1):75-6.

3. Karthikeyan G, Ganesh R, Satiasekaran M. Scarabiasis. Indian Pediatrics 2008;45(8):697-9.

4. Murray B Isman, Opender Koul, Anna Luczynski, et al. Insecticidal and antifeedant bioactivities of neem oils and their relationship to azadirachtin content. J Agric Food Chem 1990;38(6):1406-11.

5. Kudom AA, Mensah BA, Botchey MA. Aqueous neem extract versus neem powder on culex quinquefasciatus: implication for control in anthropogenic habits. J Insect Sci 2011;11:142. doi: 10.1673/031.011.14201.

6. Axe. food is medicine, http://draxe.com/neem-oil/ 